\title{
Climate change, poverty and war
}

\author{
Robin Stott
}

J R Soc Med 2007; 100:399-402

For the first time in recorded history, a single species, Homo sapiens, bears responsibility for causing significant change to the global environment. Through the burning of fossil fuels and resultant accumulation of excess carbon dioxide in the atmosphere, humanity is provoking accelerated global warming, which is already causing problems in the ecosystems on which our health depends (Boxes 1 and 2). ${ }^{1}$

These alterations in global ecology are aggravating the already parlous state of the world's most vulnerable populations, and if not tackled will lead to widespread social and economic devastation; the consequences of which, though caused by the rich, fall most heavily on the poor, in an all too familiar story. The impact of climate change is to widen the already substantial resource gulf between the rich and the poor. This gap is increasingly recognized as a significant cause of the increasing levels of despair and desperation among the dispossessed, ${ }^{2}$ emotions which frequently spiral into violent conflict. The widening gap is mirrored in the deteriorating health status of the poor (Box 3).

The security implications of climate change have been debated in the UN Security Council; Margaret Beckett, the UK Foreign Secretary at the time, stated that 'An unstable climate will exacerbate some of the core drivers of conflict'. ${ }^{3}$ The US Senate is debating a Bill to have climate change recognized as a security concern, ${ }^{4}$ and in a report on US National Security, senior American military personnel described climate change as a 'threat multiplier' for instability. ${ }^{5}$

It is not surprising that when considering the major threats to the health of humanity, the interrelated problems of climate change and the gulf between the rich and poor are seen as triggers for war, risking the ultimate health crisis of nuclear war. Resolving these interrelated risks is therefore the key to reducing the possibilities of violent conflict and improving global public health. The Intergovernmental Panel on Climate Change, the World Bank and the World Health Organization (WHO), amongst others, unequivocally state that these global problems can only be resolved through the development and implementation of a global framework. ${ }^{6-8}$ One framework which fulfils the demanding requirements of controlling atmospheric carbon dioxide levels at the same time as reducing the

Vice Chair Medact, Grayson Centre, 28 Charles Square, London N1 6HT, UK

\section{Box 1 Atmospheric carbon dioxide levels and global warming}

- Atmospheric carbon dioxide levels have risen steeply from $280 \mathrm{ppm}$ since the start of the industrial revolution and in step with increasing use of fossil fuels.

- Global temperature has risen in parallel with carbon dioxide, and the world is around $1{ }^{\circ} \mathrm{C}$ warmer than 100 years ago

- Industrialized countries bear the greatest responsibility for the present level of $380 \mathrm{ppm}$, as well as the increase of $2 \mathrm{ppm} /$ year

- The USA, with one twentieth of the world's population, uses 20 million of the 80 million barrels of oil consumed each day, Japan 5 million, Germany 3 million, and the UK 1.7 million.

- China and India are set to greatly increase their use of fossil fuels over the next few years

- The predicted temperature increase for the 21 st century is $0.15-0.6^{\circ} \mathrm{C}$ per decade

- Around $60 \%$ of the ecosystems essential to sustain life are already damaged, including many of the global carbon sinks. Destruction of these sinks not only reduce the capacity of our globe to assimilate carbon dioxide, but also releases carbon dioxide into the atmosphere

inequity between rich and poor is Contraction and Convergence, developed by the Global Commons Institute. ${ }^{9}$

\section{CURRENT GLOBAL HEALTH POLICY}

Both the World Bank and the WHO give a high priority to tackling climate change on the grounds that it is already causing health problems and developmental challenges and that these are disproportionately affecting the poor. On the other hand, the World Bank's general solution to poverty is to call for economic growth, without mentioning the need for economic growth to be kept within environmental limits. The WHO states that 'Only nationally and locally driven actions, supported by a broad and coherent international strategy, can protect global public health from the multiple threats of a rapidly changing climate.' Both organizations disseminate appropriate information; however, neither has a coherent view across the various issues with which they are working. Whilst both are clear about the need to obtain resources to offer developing nations headroom for development, the inference is that better targeted aid is the only way this can happen. But there is debate as to whether the $£ 1.2$ trillion given as aid over the last 50 years has actually relieved poverty in the most deprived regions of the world. This raises questions about the efficacy of aid as a mechanism for promoting 


\section{Box 2 Consequences of climate change}

- Thermal expansion of water plus melting land-based ice leading to sea level rises.

o 100 million people and many cities are within half a metre of present sea level.

- Expansion of range of disease vectors.

o Plasmodium falciparum already causes 500 million cases of malaria annually, and one million deaths.

- Unpredictable exposure to extremes of weather leading to flooding, disease, droughts, crop-failure and famine, and from that migration on an unprecedented scale

- Intensified competition for land, food, water and energy

- Economic disruption on a scale predicted in the Stern Report, not seen since the end of World War II

development and about the fitness for purpose of the structures that are presently charged with resolving the related issues of climate change and poverty. ${ }^{10}$

The World Bank discusses carbon trading, but there is no suggested mechanism for putting the market power of carbon trading into the hands of the poor. Neither the WHO nor the World Bank offers a clear statement about what individual health professionals can do, or how health institutions can play a part in evolving sustainable local communities. So whilst the basic information is now widely available, specific policies are not, and there is no specific global policy for which we can all call.

The present Kyoto framework, which must be replaced after 2012, has a Clean Development Mechanism whereby polluting nations are supposed to facilitate sustainable development in the yet-to-industrialize world. Polluting industries in the rich north can obtain carbon credits by investing in carbon reducing projects in the developing world. Analysis of these investments has shown that fewer than $5 \%$ have achieved sustainable development objectives. ${ }^{11}$ 'Gold standards' are now being issued to those few projects initiated by the clean development mechanism which are sustainable. This is clearly a step in the right direction but not sufficient to meet the dual needs of climate stabilization and reducing inequity.

Box 3 Deprivations and disparities which global warming will worsen

- 800 million go to bed hungry. 1 billion have no access to clean water

- Of 700 million primary school-age children, 125 million, mostly girls, don't go to school

- 2 billion people live on incomes below $\$ 1000 /$ year: 1 billion on over $\$ 30000 /$ year

- In the ten poorest countries, $25 \%$ of children die before the age of 5 ; in the ten richest countries, $0.6 \%$ die before the age of 5

- The vast majority of deaths in the poor world are from easily treatable diseases

\section{CONTRACTION AND CONVERGENCE}

\section{An exemplary global framework}

'Contraction and Convergence' is a strategy aimed at capping and then reducing carbon dioxide emissions (contraction) and by giving an equal entitlement of the capped carbon to every adult, ensuring that all get fair shares of this capped global carbon allocation (convergence).

The first step entails calculating and setting a 'global carbon budget', the amount of carbon that can be produced each year. The amount will depend on the atmospheric concentration of carbon dioxide that global partners are prepared to countenance. This budgeted amount would then be allocated as carbon entitlements on a per capita basis. The global carbon budget is then progressively reduced until the amount we are entitled to emit equals the globe's carrying capacity — estimated to be about 12 billion tonnes of carbon dioxide per year. Given the present global population, the amount to which we will ultimately be entitled is about two tonnes per person per year, an amount four times greater than the emission of the average inhabitant of Africa, but five times less than is currently emitted by the average citizen of the UK.

The atmospheric carbon dioxide concentration from which the total carbon budget is calculated is negotiable, but the consensus is that an atmospheric level of carbon dioxide of 450 parts per million (ppm), which will result in a temperature increase of around $2{ }^{\circ} \mathrm{C}$, is a tipping point beyond which there will be an exponential increase in climate related problems. Carbon budgets should be calculated with this in mind.

\section{Contraction, convergence and the majority world}

For a global framework to work, all countries must participate in setting and then reducing their carbon budget. This reduction must take into account the needs of countries that have not industrialized, as well as those that are rapidly industrializing, as contracting the use of carbonbased fuels will inevitably restrict the capacity of many countries to reap the benefits of fossil fuel driven industrialization. By giving equal entitlements of the carbon budget to each adult individual, the convergence element of the framework recognizes and provides a partial solution to this problem.

Although every individual will begin with an equal entitlement of carbon, the amount individuals emit varies considerably; people living in most African countries emit less than one tonne of carbon dioxide a year whereas people in the UK emit about 10 tonnes and those in the USA emit 20 tonnes. The initial individual entitlement within this framework is likely to be around seven tonnes of carbon dioxide a year, reducing to the sustainable level of two 
tonnes per person over an agreed period. The poor will therefore have unused carbon entitlements which they will sell to the rich, with a resultant transfer of money from rich to poor. The poor will have real market power.

Within this framework, both high and low carbon emitters will have considerable market incentives to promote low carbon development: the high emitters because they wish to minimize the amount of carbon entitlement they have to purchase, and the low emitters because if they use money generated by selling their entitlements on high carbon development, they will have fewer entitlements to sell in the future.

\section{The benefits of convergence}

Evidence from Mozambique ${ }^{12}$ suggests that money made available without strings attached will help trigger the latent entrepreneurial skills of the recipients. Given the likely market value of a tonne of carbon dioxide of between US\$60-US\$100, as indicated in the Stern report, ${ }^{13}$ selling carbon entitlements as envisaged in contraction and convergence will more than provide the US\$110 dollars per person per year that the UN millennium project believes necessary to reach the millennium development goals in Africa. Narrowing the gap in this way will have major health benefits to add to those which will be realized through mitigation of climate change.

Equal entitlements will facilitate the engagement of the majority world, effect a transfer of resources from the rich to the poor, and stimulate sustainable development that promotes the demographic transition to smaller families and restores and conserves the ecosystem. Improving the environmental, economic and social circumstances of our global populations, and capping and reducing carbon at the same time as dividing this into equal entitlements, will trigger a global virtuous cycle of activity, to counteract the present global vicious cycle of increasing inequality and environmental damage. This global virtuous cycle will help reverse the cycles of despair, desperation and anger which are so provocative of violent conflict.

\section{GLOBAL CARBON SINKS, THE CARBON BUDGET AND CARBON REDUCING POLICIES}

The globe's capacity to assimilate carbon dioxide depends crucially on the integrity of global carbon sinks. If we continue to undermine the carbon sinks by reducing the global coverage of old growth forests and peat bogs, continue to practice intensive, high-input, soil-eroding agriculture and continue to overexploit the oceans, we will have to greatly reduce the allowable carbon budget. Even more worryingly, we may not be able to prevent run-away global climate change. We must, through regulatory and rights-based mechanisms, preserve these ecosystems before they collapse or biochemical processes change major carbon sinks into carbon sources. ${ }^{14}$

Capping and reducing global carbon emissions will also enable a greater understanding and uptake of specific decarbonization measures advocated by the International Panel on Climate Change in their recent report. ${ }^{6}$ Amongst these measures are conserving energy, promoting the use of renewable fuels, building carbon-sequestering coal power stations, and a better informed debate on the need to build new nuclear power stations. However, no foreseeable technological change can compensate for all the energy we currently generate from fossil fuel. In a low-carbon future, the two billion people who are used to cheap and plentiful fossil fuel as an energy source, particularly for transport, will have to use more energy generated by human effort, prompting those of us living in rich industrialized societies to get much more exercise in our everyday lives. The physical and psychological health benefits of exercise are substantial, thus there are health benefits for the rich as well as the poor.

\section{WHAT SHOULD HEALTH PROFESSIONALS DO?}

The disparity gulf and climate change frame the policy context within which we as physicians have to act. We have a simple choice: to await the health consequences of these potential catastrophes, or to use public health models to contribute to their prevention. There are five prongs to the necessary action:

First, we need to inform, using our skills and knowledge to highlight the issues, and to show how resolving them will lead to societies where good health has a chance of flourishing.

Second, we need to affirm, by committing ourselves to live and develop within environmental limits and ensuring that the institutions within which we have influence do likewise, setting an example to the wider community.

Third, we need to advocate for a viable global framework which truly addresses the issues, such as contraction and convergence. While advocacy for a global framework is the most important role for health professionals, it is worth repeating that persuasive advocacy demands exemplary personal and institutional action and a compelling account of the benefits of the framework. Understanding the benefits and difficulties of implementing the framework of contraction and convergence is necessary for effective advocacy.

Fourth, we need to innovate. Given the track record of the past 50 years, we do not have 'fit for purpose' global structures and organizations to deliver the framework. We need to develop new forms of cooperative association between individuals, communities and ultimately nations. The loosely linked, web-based global coalitions, of which IPPNW, the Peoples Health Assembly, and the BMJsponsored Health and Climate Council are examples that offer an insight into possibilities. In association with micro 
credit banks, ${ }^{15}$ these associations could start to initiate local contraction and convergence networks, bypassing the present institutional structures. A great deal more debate is required on the kind of institutions needed to effectively implement a framework.

Fifth, and finally, we need to disseminate, recruiting as many groups as possible to support these aims and so maximize our capacity to make the necessary changes. Whilst exemplary individual action is heart warming and inspirational, structural and systemic changes and a facilitative framework are required to reverse the cycle of violent conflict in which the globe is presently mired. Contraction and convergence is such a facilitative framework.

The UN Framework Convention on Climate Change ${ }^{16}$ is the global body with responsibility for mapping our postKyoto future. The overseeing board, the Conference of the Parties, meets annually, with the next meeting in Nusa Dua, Bali, between 3 and 14 December 2007. Here will be an important opportunity for civil society, strongly supported by health interests, to insist that an appropriate framework replaces Kyoto. Advocacy by health professionals for contraction and convergence will promote global public health and ease the pressure on the drivers of war.

Competing interests None declared.

\section{Guarantor RS}

Contributorship RS is the sole contributor

\section{REFERENCES}

1 World Health Organization. Ecosystems and Human Well-Being: Health Systems. Geneva: WHO, 2005
2 Wolfenson J. BBC Today Programme. 21 June 2007. Available at http:// www.bbc.co.uk/radio4/today/listenagain/zthursday_20070621.shtml (accessed 8/07/2007)

3 Leopold E. UK Puts Climate Change in U.N. Council. Reuters, 17 April 2007. Available at http://www.reuters.com/article/environment News/idUSN1736824820070418 (accessed 8/07/2007).

4 Durbin D. Durbin, Hagel: Global Warming Poses Serious Threat To National Security. 28 March 2007. Available at durbin.senate.gov/record. cfm?id=271514 (accessed 8/07/2007).

5 CNA Corporation. National Security and the Threat of Climate Change. Alexandria, Virginia: CNAC, 2007. Available at: http:// securityandclimate.cna.org/ (accessed 8/07/2007)

6 Intergovernmental Panel on Climate Change. Summary for Policy Makers from Working Group III Climate Change 2007: Mitigation of Climate Change. Available at www.ipcc.ch/SPM040507.pdf (accessed 8/07/2007)

7 World Health Organization. Climate change and health. Available at www.who.int/globalchange/climate/en/ (accessed 8/07/2007)

8 World Bank. Climate Change. Available at http://go.worldbank.org/ W13H8ZXSD1 (accessed 8/07/2007)

9 Global Commons Institute. Contraction and Convergence. Available at www.gci.org.uk (accessed 8/07/2007)

10 Easterly W. Was Development Assistance a Mistake? Paper presented at the Annual meeting of the American Economic Association, New Orleans, January 2007. Available at http://www.aeaweb.org/annual_mtg papers/2007/0106_1430_2003.pdf (accessed 8/07/2007)

11 The Gold Standard Foundation. Available at http://www. cdmgoldstandard.org/ (accessed 8/07/2007)

12 Hanlon J. Is it possible just to give money to the poor? Development Change 2004; 35: 375-83

13 Stern N. Stern Review on the Economics of Climate Change. London: HM Treasury. Available at http://www.hm-treasury.gov.uk/ independent_reviews/stern_review_economics_climate_change/ stern_review_report.cfm (accessed 23/07/2007)

14 Ernsting A, Rughani D. Heading in the wrong direction: Critical Ingredients for Stabilizing Climate. In press

15 Yunus M. The Grameen Bank at a glance. May 2007. Available at http:// www.grameen-info.org/bank/GBGlance.htm (accessed 8/07/2007)

16 United Nation Framework Convention on Climate Change. Available at http://unfccc.int/2860.php (accessed 8/07/2007) 